\title{
GCU
}

Glasgow Caledonian

University

University for the Common Good

\section{Maintenance engineering management of a LNG plant critical system: a case study of gas turbine dry gas seal}

Pereira, E.; Alkali, B.M.; Niculita, O.

Published in:

Proceedings of the 10th IMA International Conference on Modelling in Industrial Maintenance and Reliability

DOI:

10.19124/ima.2018.001.20

Publication date:

2018

Document Version

Author accepted manuscript

Link to publication in ResearchOnline

Citation for published version (Harvard):

Pereira, E, Alkali, BM \& Niculita, O 2018, Maintenance engineering management of a LNG plant critical system: a case study of gas turbine dry gas seal. in $\mathrm{P}$ scarf (ed.), Proceedings of the 10th IMA International Conference on Modelling in Industrial Maintenance and Reliability. 10th IMA International Conference on Modelling in Industrial Maintenance and Reliability, Manchester, United Kingdom, 13/06/18.

https://doi.org/10.19124/ima.2018.001.20

\section{General rights}

Copyright and moral rights for the publications made accessible in the public portal are retained by the authors and/or other copyright owners and it is a condition of accessing publications that users recognise and abide by the legal requirements associated with these rights.

Take down policy

If you believe that this document breaches copyright please view our takedown policy at https://edshare.gcu.ac.uk/id/eprint/5179 for details

of how to contact us. 


\title{
Maintenance engineering management of a LNG plant critical system: a case study of gas turbine dry gas seal
}

\author{
E. Pereira, B.M Alkali \& O. Niculita \\ Department of Engineering, School of Engineering and Built Envirinment, Glasgow Caledonina University, \\ Glasgow, G4 OBA, United Kingdom. Eloi.Pereira@gcu.ac.uk, Babakalli.alkali@gcu.ac.uk, \\ Octavian.Niculita@gcu.ac.uk
}

\begin{abstract}
This paper focuses on maintenance management of critical equipment of a New Liquefied Natural Gas (LNG) plant. The challenges associated with the risk of failure affect the operational conditions of the plant equipment, and also the recommendations by the original equipment manufacturer (OEM) to maintain critical system is a difficult task. In this paper a case study of a new gas turbine design within an LNG plant is considered. The maintenance cost, operation and availability are some of the most important concerns to the gas turbine operators. Majority of the gas turbine maintenance are related to the replacement and repair of hot section static parts. A review of the operating and maintenance practices for heavy-duty gas turbines and others critical equipment, with emphasis placed on the types of inspections and factors that influence maintenance schedules is presented. The Reliability Centred Maintenance (RCM) modeling and criticality analysis approach is used to analyse historical failure and maintenance data. To compliment the accuracy of data information careful consultation with the operators is conducted and we test the goodness of fit of using a Weibull model for the analysis. A maintenance optimisation model is discussed and an attempt is made to model the failure pattern to determine and recommend cost effective maintenance management schedule for the gas turbine dry gas seal.
\end{abstract}

\section{Introduction}

There are a number of approaches an organisation can take to maintain rotating machinery, and often an organization will practice a number of different maintenance philosophies at once. To detect a problem well before failure occurs, and to make changes to improve equipment reliability, it is important to understand why machines fail in the first place. The source of machine failure can start on the design and end with poor maintenance practices and operating conditions. The way the machine is manufactured, the way it is installed, and the way it is overhauled all contribute to the ultimate life of the machine. All rotating machinery, like gas turbines and gas compressors, will vibrate. The level of the vibration and the pattern of the vibration tell us something about the internal condition of the rotating component. (Vibration training inter oil PNG 2010). Maintenance and reliability engineers deploy two basic strategies to insure asset reliability: predictive maintenance and proactive maintenance. No matter how often we continuously monitoring an equipment, we cannot influence the probability of failure we can only hope to find the problem early enough that corrective action can be planned for a time that is least disruptive and costly to the organisation. In this paper, the dry gas seal is investigated due to several sources of failure which can affect seal integrity (such as wrong installation, prolong reverse rotation, material compatibility, excessive vibration or alignment, loss of film stiffness across the sealing faces, ingress of solids or liquids into the seal cavities will cause a reduction in performance). The Reliability Centered Maintenance (RCM) approach discussed by Moubray (1997) is an adequate approach to determine the maintenance requirement of complex physical asset in its operating context. In this paper RCM is conducted on the dry gas seal to give a better insight of the failure modes and link of the failure modes to the historical failure of dry gas 
seal types. The dry gas seal is considered as a single point failure resulting to production losses. A brief technical description and the operational process of the dry gas seal component as discussed in Section 2.

\section{Dry gas seal}

Dry gas seals are designed to operate with clean dry gas. The sealing gas is normally supplied during operation from the discharge flow of a selected compressor. The dry gas seal has the following advantages;

- System simplicity: Simplification of the system and therefore greater reliability and reduced maintenance (elimination of the overhead tank for the seals, of the oil pumps, of the traps, of the gas separators)

- No process gas contamination: Elimination of oil transfers, through seals, in the compressed gas.

- Increased efficiency: Economy of the system due to the reduction of oil consumption through seal, to the energy consumption (no oil pumps), to the improved reliability and availability.

- Minimization of process gas discharge: To the atmosphere during normal running (Dry gas seals secondary vent versus oil seals traps vent).

- Reduction of fire risk due to burst of pipes or pipe fitting at high pressure.

The dry gas seal consist of stationary and rotating parts as illustrated in the cross sectional view diagram in Figure 1. During start-up conditions, the seal gas is supplied from the fuel gas system or another compressor source.

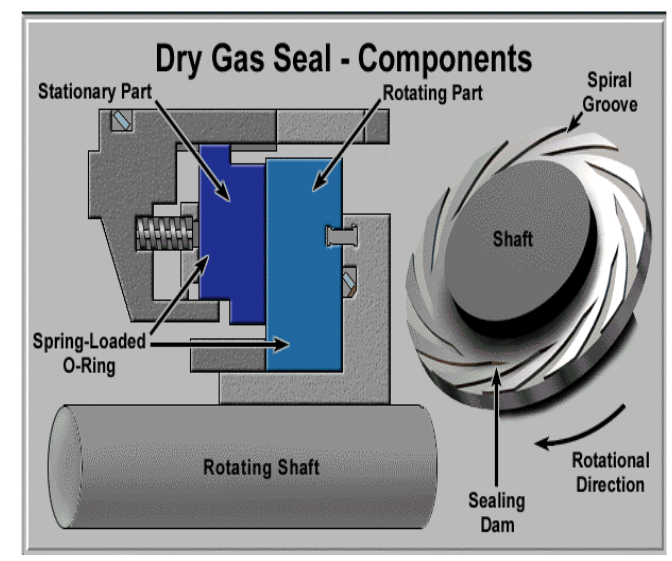

Figure 1: Cross sectional view of dry gas seal components

The seal gas goes through a duplex set of filters, a differential pressure control valve with an orifice bypass (for minimum flow). There are different type of dry gas seal which include; single seal, double seal and the tandem seal.

Single seal

Single seal is used where gas is sealed at relatively moderate pressure, and where a small amount of leakage into the atmosphere does not present a problem. 


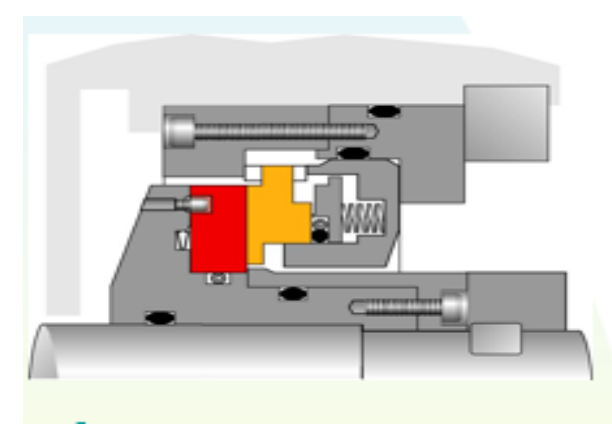

Figure 2: Single seal configuration

Double seal

The double seal has sealing modules facing each other and sometimes fitted with common rotating element. Double seal arrangement provides a positive barrier to process gas through the use of buffering with inert gas. Buffer gas is normally set at higher pressure than sealed process gas, leakage between inert gas and process gas can occur. The double seal prevents any trace of process gas from escaping to atmosphere. The diagram in Figure 3 give and example of double seal configuration. (ADGAS 2006)

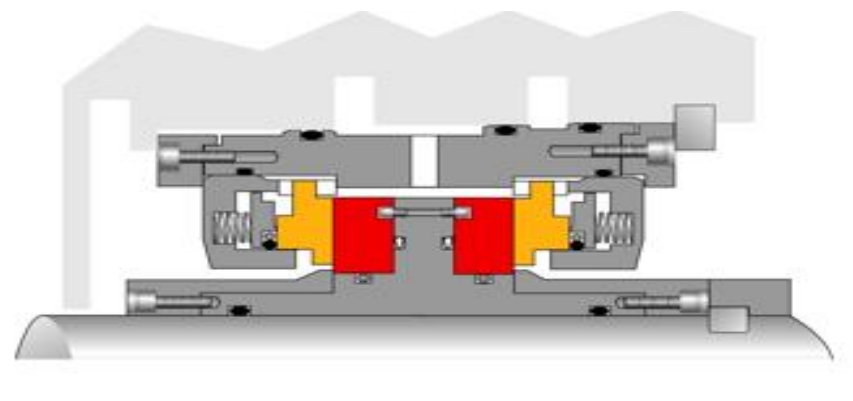

Figure 3: Double seal

Usage of a double seal arrangement is mainly to seal toxic or hazardous gases or where process is being protected from outside contaminants.

\section{Tandem seal}

The Tandem seal is type of dry gas seal and the tandem seal arrangement consist of a primary seal and a secondary seal, contained within a single cartridge. An example of the tandem seal set is presented in Figure 4. The sealing modules can share sealing load, or more commonly, one seal would handle full pressure drop while other seal would run as a standby or back up seal with zero pressure differential, this back up seal then functions as an additional barrier between the process gas and atmosphere. Higher pressure may require triple tandems where two seals share the sealing load and the third is a backup and barrier seal, (Stahley, 2001). 


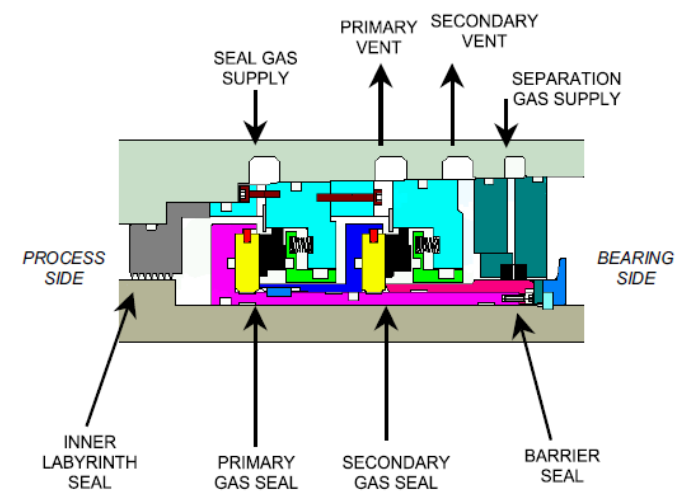

Figure 4: Tanden seal

\section{Dry gas seal maintenance and failure}

The dry gas seal has a variety of challenges related to maintenance, storage and failure. The seal require adequate maintenance, and proper care should be utilized to keep the gas seal in their optimum performance condition during operation. The dry gas seal is always exposed to oil or other contaminations. Although the seals are normally reliable in operation, however they can be damaged as a result of incorrect assembly or handling, and the spear seals must be assembled with the appropriate installation plates in order to hold the rotating and stationary elements in alignment.

If the seals are to be fitted to the compressor, it is necessary to ensure that the seal faces are not contaminated with oil. This is necessary to prevent the seal faces from wringing together. During any storage period it is necessary to keep the seals free from all solid and liquid contaminants either which can damage the seal faces during compressor start up and operation.

\section{Reliability Centered Maintenance}

The Reliability Centred Maintenance (RCM) concept is one of most useful tools that is established by the aeronautics business group in the early of 1970s (Brauer D. and Brauer G. 1987). This maintenance tool had been developed for failure analysis of equipment to reduce maintenance tasks and unnecessary works to propose adequate maintenance program (Demers 2005). By doing this, the availability and reliability are inclined to increase and hence decrease maintenance costs (Ramli and Arffin 2012). These are the seven basic steps of the RCM process which can lead to the achievement of best maintenance practices, based on increasing the reliability, safety and cost saving (Moubray 1997). The RCM modeling approach is considered in this paper.

\subsection{RCM investigation and analysis}

RCM is conducted on the on the dry gas seal and the result indicates that debris from the seal gas filter was freed into the clean side of the filter, this debris preferentially flowed through the drive end seal of the compressor. The increased seal gas flow across the seal is attributed to one: 
- Wear of seal face due to debris

- Seal hang-up due to debris

The possible causes of the seal failure are believed to be:

- Debris passing the seal gas filters due to saturation and an impulse of gas being introduced.

- Saturated seal gas filters due to insufficient cleaning of the seal gas lines after construction work. Contributing factors of the seal failure are believed to be:

- Debris introduced from the seal drain.

- Seal gas Differential Pressure Control Valve being $100 \%$ open when high-pressure seal gas is introduced.

The seal gas filters the high differential pressures lead to debris had possibly passed through the seal gas filter and flow to the seals. This validates that debris was in the seal gas flow to the dry gas seals. From our investigation we found that $99 \%$ of the DGS failures during commissioning is due to none seal related problems, such as foreign contaminates in the seals cavity, seals installation errors, alignment problems, piping problems, liquid inside piping and compressor casing, instrument problems. Contact between the faces is normally a primary cause of gas seal failure, face contact due to mechanical operation are, wrong installation., prolong reverse rotation., material compatibility, excessive vibration-alignment, reverse pressurization, loss of film stiffness across the sealing faces, damaged elastomers during installation.

It was also deduced that $80 \%$ of the seal failures are due to seal gas contaminations, continuous supply of clean and dry seal gas is one of the most important requirements for trouble free operation of dry gas seal. A study from DGS (2012) concluded that dry gas seal reliability is equal to compressor availability. Dry gas seal contamination is predominantly caused by inadequate quality and or pressure of the gas in the seal cavity. Ingress of solids and or liquids into the seal cavities will cause a reduction in performance. Reduction in performance will eventually lead to instability of the fluid film between the rotating and stationary sealing faces resulting in loss of aerodynamic lift. Loss of aerodynamic lift at the seal faces can lead to a catastrophic failure scenario. (DGS 2012)

\section{Maintenance optimisation}

Many different types of maintenance optimization models have been developed and examples of such models can be found in (Dekker 1996; Dekker and Scarf 1998). The literature gives a nice overview of maintenance models distinguishing such policies as age replacement, block replacement, failure limit, repair limit, sequential, and repair counting; optimization criteria such as cost, availability, failure rate limits, cost and reliability; different time horizons over which the criteria are measured, and different types of repair. It is acknowledged that one of the reasons that many models have found limited application is that the assumptions made are typically rather strong. (Christer 1984) noted the preventive maintenance acitvity is considered to be the most difficult maintenace to model in the filed of maintenance.

\subsection{Weibull model}

In estimating the failure rate of the dry gas seal the hazard function is used and a Weibull model is considered as adequate as it is a monotonic function capable of capturing the improvement and deterioration 
of the dry gas seal. For the Weibull model for $t \geq 0$, this implies that the failure rate $\lambda(t)=h(t)$, therefore the expression of the hazard function of the Weibull Power law process is given as

$$
h(t)=t^{1}
$$

The Reliability function is

$$
R(t)=1 \quad F(t)=\exp (\quad t)
$$

and then the density function of the Weibull distribution is then

$$
f(t)=t^{1} \exp (\quad t)
$$

The likelihood function for the power-law process will then be proportional to the product of the total probability of the intensities and it is given as

$$
L(, ; D) \propto\left\{\prod_{i=1}^{n}\left(t_{i}\right)\right\} \exp \left(t_{0}\right) .
$$

Where $D$ is the observed data set and $\alpha, \beta$ is the scale and shape parameters respectively. The probability of the underground cable failure intensities can be differentiated with respect to the parameter $(\alpha, \beta)$ and the resulting derivatives are set to zero to give the maximum. Thus, the log-likelihood is given as

$$
\ell(, ; D)=n \log +n \log +\left(\begin{array}{lll}
1) & n \\
i=1 & \left(\log t_{i}\right. & t_{0}
\end{array}\right)
$$

Differentiating the function (5) above with respect to the shape parameter $\beta$ and setting the derivative to zero. Multiplying both side of equation (6) by the shape parameter $\beta$

$$
\stackrel{\ell}{\ell}: 0+\frac{n}{+}+{ }_{i=1}^{n} \log t_{i} \quad t_{0} \log t_{0}=0
$$

we then substitute the scale parameter in equation (7) above, this can be obtained by differentiating the

$$
n+{ }_{i=1}^{n} \log t_{i} \quad\left(\log t_{0}\right) \quad t_{0}=0,
$$

equation (5) with respect to $\alpha$ and setting the derivative to zero 


$$
\Rightarrow n+\left(\sum_{i=1}^{n} \log t_{i} \quad n \log t_{0}\right)=0 .
$$

Therefore, the model closed form MLEs for the shape parameter $\beta$ and scale parameter $\alpha$ is given as

$$
=\frac{n}{n \log t_{o}{ }_{i=1}^{n} \log t_{i}}, \quad=\frac{n}{t_{o}} .
$$

The maximum likelihood estimate of the shape and scale parameters is given above.

\subsection{Weibull analysis}

The Weibull distribution has been adopted to analyze the time-to-failure of dray gas seal. When it is used in predicting number of failures for those aging related populations of seals and where failure data is more likely to be homogeneous. In cases of early failures, the present authors applied the linear model to determine the goodness of fit of the Weibull distribution to two sets of data; one from the double seal and tandem seal respectively. As shown in Figure 5, each data point represents a failure that has been processed and the lines represent the linear fit of these points. R-Square is the degree of fitting. The closer R-Square value is to 1, the better the fitting is. Also in Figure 5, the horizontal axis is the logarithmic of " $t$ " which stands for "time-to-failure" of the failed cables, while the vertical axis " $F(t)$ " represents the cumulative distribution function of seals. The Weibull model give a good fitting result, as can be seen in Figure 5(a). However with the tandem seal failures, The R-square value of approximately 0.826 is not acceptable as shown in Figure 5(b) showing that the set of data does not obey Weibull distribution. The reason may be due to a lack of data homogeneity.

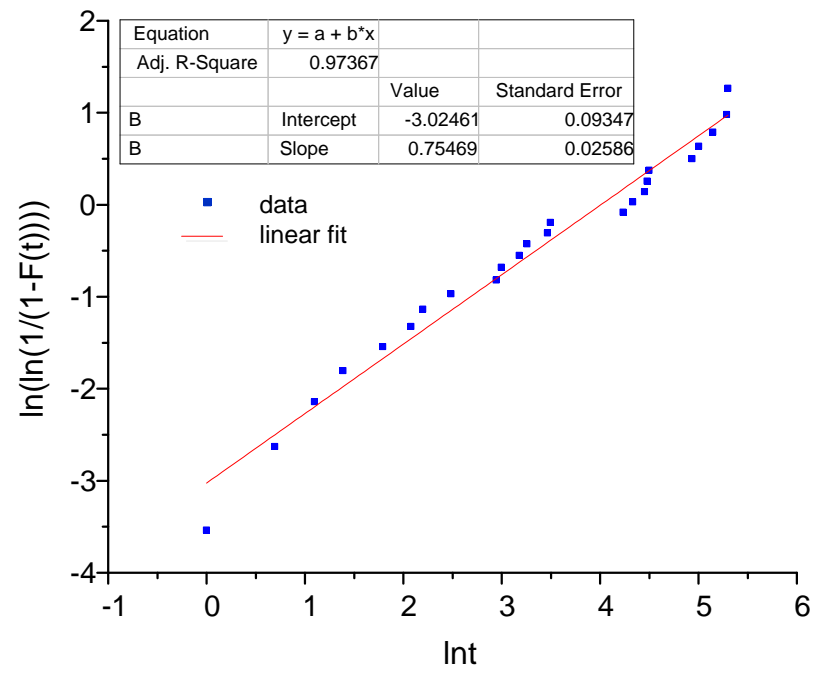

(a) Double seal

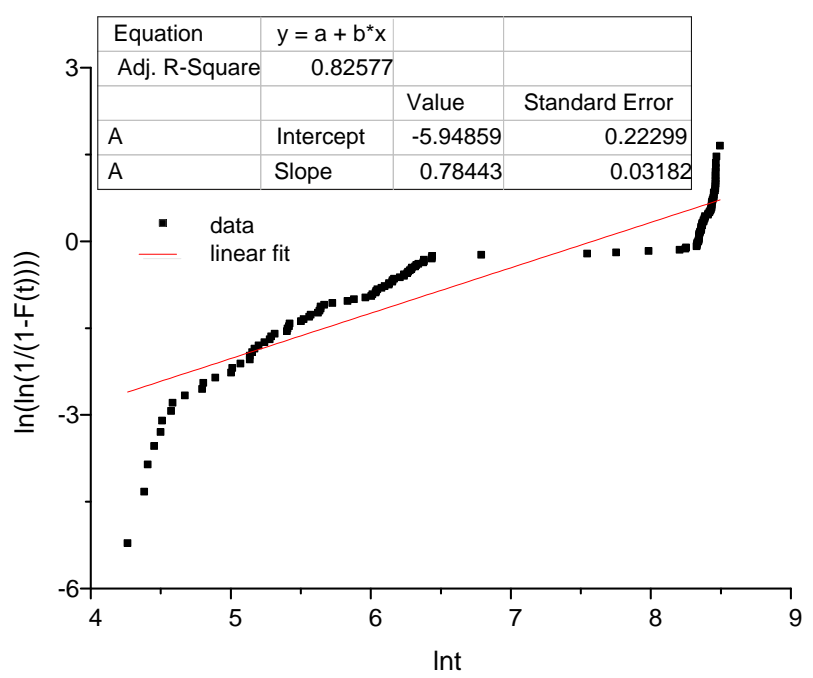

(b) Tandem seal

Figure 5: Analysis of Double and Tanden seal using Weibull distribution 


\section{Discussions}

The main assumption of the proposed model is that $T_{i}$ are drawn randomly from a Weibull distribution. From the data we can observe what causes the dray seal to fail. The actual data consists of a sequence of failure modes, which are followed by either maintenance or a failure. However, this reflects a practical issue that is nowadays quite often the case: Underlying systems reliability may be measured during maintenance. However, during operation there are lots of things, often external to the gas turbine seal failure modes, which can cause the seal to fail. In this way it is possible to have a high measured reliability during maintenance times and a much lower availability in practice. Condition monitoring information of the seals is also required to model how changes to current set up would affect availability. Investigation into the dataset collected is still underway and we intend to fit the proposed model and present results in future publications.

\section{Conclusions}

This paper present failure analysis result conducted on dry gas seals of a GT in an LNG plant. The result from the application show that approach is used to establish link with reliability analysis. The RCM modeling approach is used to conduct Weibull analysis model. The application of the Weibull model to the dry gas seal failure data is still on-going and the results will be presented at the conference.

\section{Acknowledgement}

I would like to thank Dr Babakalli and Dr Octavian, for all the technical support and guidance to get this paper done on professional manner.

\section{References}

John S. Stahley (2001), Dry Gas Seal System Design Standards for Centrifugal Compressor Applications. John S. Stahley (2001), Design, Operation, and Maintenance Considerations for Improved Dry Gas Seal Reliability in Centrifugal Compressors

API Standard 614, 1999 Lubrication Shaft-Sealing and Control-Oil Systems for Special-Purpose Application, Fourth Edition, API, Washington, D.C

Dry Gas Seal Training Manual 2012 Maintenance and Operation

Thorp, Joseph. (2008). Improving Dry Gas Seal Reliability

Brauer, D. and Brauer, G. (1987) Reliability-centered maintenance. Reliability, IEEE Transactions on, 36(1), pp.17-24. ISSN 0018-9529

Demers, J. (2005) Reliability centred maintenance. CIM Bulletin. Vol. 98(1086), pp. 50. ISSN 0317-0926. Moubray, J. (1991) Reliability-centered maintenance. New York: Industrial Press.

Moubray, J. (1997) Reliability-centered maintenance. New York: Industrial Press.

Ramli, R. \& Arffin, M.N. (2012) Reliability Centered Maintenance in Schedule Improvement of Automotive Assembly Industry. American Journal of Applied Sciences. Vol. 9, no. 8, pp. 1232-1236. ISSN 1546-9239

Compressor training manual 2011 Operation and Maintenance

Adgas das Insland compressor training 2006 Turbomachinery 
Christer, A. H. and W. M. Waller. 1984. Operational Research Approach to Planned Maintenance: Modelling PM for a Vehicle Fleet. Journal of the Operational Research Society 35: 967-984.

Crocker, J. and U. D. Kumar. 2000. Age-related maintenance versus reliability centred maintenance: a case study on aero-engines. Reliability Engineering \& System Safety, Volume 67, Issue 2, February 2000, Pages 113-118

Dekker, R., 1996. Applications of maintenance optimization models: A review and analysis. Reliability Engineering \& System Safety 51(3): 229-240.

Dekker, R. and P. A. Scarf. 1998. On the impact of optimisation models in maintenance decision making: the state of the art. Reliability Engineering \& System Safety 60(2): 111-119. 